Neurosurgery

Issue: Volume 41(2), August 1997, pp 403-410

Copyright: Copyright $\odot$ by the Congress of Neurological Surgeons

Publication Type: [Technique Assessments]

ISSN: 0148-396X

Accession: 00006123-199708000-00013

Keywords: Cerebrovascular disease, Image-guided neurosurgery, Magnetic resonance imaging, Phase contrast magnetic resonance angiography, Three-dimensional reconstruction

[Technique Assessments]

\title{
Computer-assisted Surgical Planning for Cerebrovascular Neurosurgery
}

Nakajima, Shin MD; Atsumi, Hideki MD; Bhalerao, Abhir H. PhD; Jolesz, Ferenc A. MD; Kikinis, Ron MD; Yoshimine, Toshiki MD, PhD; Moriarty, Thomas M. MD, PhD; Stieg,

Philip E. PhD, MD

\section{Author Information}

Surgical Planning Laboratory (SN, HA, AHB, FAJ, RK), Department of Radiology, and Division of Neurosurgery (TMM, PES), Department of Surgery, Brigham and Women's

Hospital, Harvard Medical School, Boston, Massachusetts, and Department of Neurosurgery (TY), Osaka University Medical School, Osaka, Japan

Received, October 31, 1996. Accepted, March 12, 1997.

Reprint requests: Philip E. Stieg, Ph.D., M.D., Division of Neurosurgery, Brigham \& Women's Hospital, 75 Francis Street, Boston, MA 02115.

\section{Abstract}

OBJECTIVE: We used three-dimensional reconstructed magnetic resonance images for planning the operations of 16 patients with various cerebrovascular diseases. We studied the cases of these patients to determine the advantages and current limitations of our computer-assisted surgical planning system as it applies to the treatment of vascular lesions.

METHODS: Magnetic resonance angiograms or thin slice gradient echo magnetic resonance images were processed for three-dimensional reconstruction. The segmentation, based on the signal intensities and voxel connectivity, separated each anatomic structure of interest, such as the brain, vessels, and skin. A threedimensional model was then reconstructed by surface rendering. This three-dimensional model could be colored, made translucent, and interactively rotated by a mouse-controlled cursor on a workstation display. In addition, a three-dimensional blood flow analysis was performed, if necessary. The three-dimensional model was used to assist in three stages of surgical planning, as follows: 1) to choose the best method of intervention, 2) to evaluate surgical risk, 3) to select a surgical approach, and 4) to localize lesions.

RESULTS: The generation of three-dimensional models allows visualization of pathological anatomy and its relationship to adjacent normal structures, accurate lesion volume determination, and preoperative computerassisted visualization of alternative surgical approaches.

CONCLUSION: Computer-assisted surgical planning is useful for patients with cerebrovascular disease at various stages of treatment. Lesion identification, therapeutic and surgical option planning, and intraoperative localization are all enhanced with these techniques.

Current advances in computer and imaging technologies have made it possible to generate precise threedimensional reconstructed images in several hours using routine clinical radiological data $(2,6,17,19,25)$. We have created a complete computer-assisted surgical planning system to provide three-dimensional models for surgery $(14,17)$ and have already applied it in more than 120 cases.

For cerebrovascular disease, conventional or digital subtraction angiography is used to plan treatment. These modalities generate a high-resolution image, but it is sometimes difficult to understand the precise anatomy of the lesion and related structures because they are only two-dimensionally projected images. On the other hand, the complementary and less invasive modalities, such as computed tomography, magnetic resonance(MR) imaging, and MR angiography, contain three-dimensional volume data. More recently, three-dimensional computed tomographic (CT) angiography has been developed and applied for diagnostic and therapeutic purposes $(2,6,16,22,25)$.

These three-dimensional reconstructed images are expected to help a surgeon select the most appropriate therapeutic intervention. This is achieved through "preoperative simulation" of the surgical approach and real-time intraoperative navigational methods. In addition, precise three-dimensional flow analysis facilitates image rendering of blood flow direction and velocity and thereby allows differentiation of the venous and arterial anatomy in a noninvasive fashion. This is useful in understanding the structure of complex vascular anomalies, such as arteriovenous malformations (AVMs). For this article, we studied 16 cases of various cerebrovascular pathological abnormalities with computer-assisted surgical planning. We discuss the usefulness, limitations, and future possibilities of our system in the treatment of cerebrovascular diseases.

\section{PATIENTS AND METHODS}

Patients

We created three-dimensional reconstructions from MR images and used them for surgical planning for 16 patients (age range, 15-74 yr; 5 male and 11 female patients) with cerebrovascular diseases (eight AVMs, two 
aneurysms, one suspected aneurysm, four cavernous malformations, and one carotid stenosis). Each patient's profile is detailed in Table 1.

\begin{tabular}{|c|c|c|c|c|c|c|}
\hline $\begin{array}{l}\text { Patient } \\
\text { No. }\end{array}$ & $\begin{array}{l}\text { Age } \\
\text { (yri)Sex }\end{array}$ & Disease & $\begin{array}{l}\text { Surgical } \\
\text { Planning }\end{array}$ & Therapy & Outcome & Comment \\
\hline 1 & $74 / \mathrm{M}$ & Bilateral carotid stenosis & 1 & $\begin{array}{l}\text { Carotid } \\
\text { endarterectomy }\end{array}$ & Excellent & $\begin{array}{l}\text { Surgery performed on basis of three- } \\
\text { dimensional MR images }\end{array}$ \\
\hline 2 & $38 / \mathrm{M}$ & Lt. parietal AVMs & $R, A$ & Removal & Excellent & $\begin{array}{l}\text { Localization based on three dimensional } \\
\text { anatomy near eloquent cortex }\end{array}$ \\
\hline 3 & $68 / F$ & $\begin{array}{l}\text { Lt. intracavernous } \\
\text { aneurysm }\end{array}$ & 1 & $\begin{array}{l}\text { Follow-up } \\
\text { examinations }\end{array}$ & $\begin{array}{l}\text { Poor (because } \\
\text { of other } \\
\text { pathological } \\
\text { abnormalities }\end{array}$ & Patient refused therapy \\
\hline 4 & $30 / F$ & $\begin{array}{l}\text { Lt. parietal cavernous } \\
\text { malformation }\end{array}$ & $\mathrm{D}, \mathrm{A}$ & Removal & Excellent & Localization near motor/sensory cortex \\
\hline 5 & $26 / F$ & $\begin{array}{l}\text { Lt. cerebellar cavernous } \\
\text { malformation }\end{array}$ & $\mathrm{I}, \mathrm{A}$ & Removal & Excellent & $\begin{array}{l}\text { Plan surgical approach based on three- } \\
\text { dimensional MR images }\end{array}$ \\
\hline 6 & $39 / 7$ & $\begin{array}{l}\text { Rt. cerebellar } \\
\text { hemispheric AVMs }\end{array}$ & 1 & Removal & Excellent & $\begin{array}{l}\text { Three-dimensional MR images used to } \\
\text { define feeding artery and draining } \\
\text { vein }\end{array}$ \\
\hline 7 & $39 / \mathrm{F}$ & Lt. post. temporal AVMs & $1, R$ & Radiosurgery & Excellent & $\begin{array}{l}\text { Three-dimensional MR images used to } \\
\text { review potential surgical approach }\end{array}$ \\
\hline 8 & $15 / M$ & $\begin{array}{l}\text { Bilateral ant. pericallosal } \\
\text { AVMs }\end{array}$ & I,R,A & Removal & Excellent & $\begin{array}{l}\text { Three-dimensional MR images used to } \\
\text { define feeding artery and draining } \\
\text { vein }\end{array}$ \\
\hline 9 & $46 / \mathrm{M}$ & $\begin{array}{l}\text { Lt. MCA aneurysm } \\
\text { suspected }\end{array}$ & 1 & $\begin{array}{l}\text { Follow-up } \\
\text { examinations }\end{array}$ & Excellent & $\begin{array}{l}\text { Three-dimensional MR images used to } \\
\text { make diagnosis }\end{array}$ \\
\hline 10 & $37 / M$ & $\begin{array}{l}\text { Lt. mesial occipital } \\
\text { trigonal AVMs }\end{array}$ & $1, \mathbb{R}$ & $\begin{array}{l}\text { Embolization } \\
\text { plus removal }\end{array}$ & Excellent & $\begin{array}{l}\text { Three-dimensional MR images used to } \\
\text { review surgical approach and } \\
\text { localization }\end{array}$ \\
\hline 11 & $35 / \mathrm{F}$ & $\begin{array}{l}\text { Rt. cerebellar } \\
\text { hemispheric AVMs }\end{array}$ & $\mathrm{I}, \mathrm{R}, \mathrm{A}$ & $\begin{array}{l}\text { Embolization } \\
\text { plus removal }\end{array}$ & Excellent & $\begin{array}{l}\text { Three-dimensional MR images used to } \\
\text { define feeding artery and draining } \\
\text { vein }\end{array}$ \\
\hline 12 & $18 / \mathrm{M}$ & Lt. trigonal AVMs & $\mathrm{I}, \mathrm{R}, \mathrm{A}$ & Removal & Excellent & $\begin{array}{l}\text { Three-dimensional MR images used to } \\
\text { review surgical approach }\end{array}$ \\
\hline 13 & $42 / \mathrm{F}$ & Rt. temporoccipital AVMs & $I, R$ & Radiosurgery & Excellent & $\begin{array}{l}\text { Three-dimensional MR images used to } \\
\text { define deep draining veins and } \\
\text { anatomic relationship }\end{array}$ \\
\hline 14 & $68 / 7$ & Lt. ICA aneurysm & 1 & $\begin{array}{l}\text { Wrapping plus } \\
\text { placing coils }\end{array}$ & Excellent & $\begin{array}{l}\text { Three-dimensional MR images used for } \\
\text { aneurysm localization }\end{array}$ \\
\hline 15 & $39 / \mathrm{f}$ & $\begin{array}{l}\text { Lt. temporal cavernous } \\
\text { malformation }\end{array}$ & R,A & Removal & Excellent & $\begin{array}{l}\text { Three-dimensional MR images used for } \\
\text { intraoperative localization near } \\
\text { elocquent cortex }\end{array}$ \\
\hline 16 & $35 / \mathrm{F}$ & $\begin{array}{l}\text { Lt. temporal cavernous } \\
\text { malformation }\end{array}$ & $\mathrm{R}, \mathrm{A}$ & Removal & Excellent & $\begin{array}{l}\text { Three-dimensional MR images used for } \\
\text { intraoperative localization near } \\
\text { eloquent cortex }\end{array}$ \\
\hline
\end{tabular}

'LL., left; Rt., right; AVMs, arteriovenous malformations; post., posterior; ant., anterior; MCA, middle cerebral artery; ICA, internal carotid artery; 1 , for choosing the intervention; $R$, for assessing surgical risk; A, for assessing surgical approach; MR, magnetic resonance.

TABLE 1. Patient's Profile and Outcome ${ }^{a}$

MR data acquisition and transfer

The MR data were obtained using a 1.5-T MR unit (Signa; GE Medical Systems, Milwaukee, WI). A series of 124 contrast-enhanced images, three-dimensional spoiled gradient recalled acquisition in steady state(thickness, 1.5 $\mathrm{mm}$; matrix, $256 \times 256$; frame of view, $220-240 \mathrm{~mm}$ ), and one of two MR angiographic series, either a series of 300 three-dimensional phase contrast angiograms (thickness, 1.0-1.5 mm; matrix, $256 \times 256$; frame of view, 200-240 mm; encoding velocity, $10-60 \mathrm{~cm} / \mathrm{s}$ ) or a series of 60 three-dimensional time-of-flight angiograms(thickness, 1.0-1.5 mm; matrix, $256 \times 256$; frame of view, $200-240 \mathrm{~mm}$ ) were acquired. The data were digitally transferred to the Sun computer workstation (SPARC Station 20; Sun Microsystems, Inc., Mountain View, CA) via a computer network.

Image processing

Each image was preprocessed to reduce noise using anisotropic diffusion filtering (13). After preprocessing, a segmentation, based on signal intensities and a voxel connectivity $(7,8)$, was performed afterward if the initial segmentation was inappropriate. From these labeled images, three-dimensional objects of the brain, vessels, skin, and other related structures were reconstructed using the marching cubes algorithm and a surface-rendering method (7-9). These objects were then integrated and displayed on a Sun computer workstation (Ultra-1; Sun 
Microsystems, Inc.) and a graphic accelerator (Creator3D; Sun Microsystems, Inc.) with three-dimensional display software (LAVA; Sun Microsystems, Inc.). With this software, each object can be individually colored, made translucent, removed, rotated, translated, and scaled by the viewer. The entire process, from scanned data to three-dimensional model, took 3 to 15 hours per patient (average time, $6 \mathrm{~h}$ ). For a complicated case of AVMs, a flow analysis was performed using velocity information in the three orthogonal directions of three-dimensional phase contrast MR angiography (4) to define feeding arteries and draining veins.

\section{Surgical planning}

We used the three-dimensional model for four purposes, as follows: 1) to facilitate selection of the appropriate intervention (i.e., observation, embolization with or without surgery, surgery alone, or radiosurgery); 2) to assess operative risk in surgical cases; 3 ) to visualize the normal and pathological relationships and select the surgical approach noninvasively and preoperatively; and 4) to localize lesions intraoperatively in conjunction with video registration $(14,20)$. The models were also used preoperatively to enhance resident training.

\section{Outcome}

Patients were assessed immediately after treatment and 3 months after invasive procedures. Both patients who received radiation treatment underwent 2-year follow-up examinations. Outcome was graded as excellent in patients with no new neurological deficits, good in patients with new but minor neurological deficits, and poor in patients requiring assistance.

\section{RESULTS AND ILLUSTRATIVE CASES}

Of the 16 patients preoperatively evaluated in the surgical planning laboratory, 9 underwent surgery alone, 2 underwent embolization plus surgery, 2 were treated with stereotactic radiosurgery, 1 underwent surgery plus intravascular coil placement, and 1 did not need therapy after a correct diagnosis was rendered. The last patient refused any therapy. The imaging data collected in the laboratory for all cases was needed to obtain a diagnosis. The pre- and postoperative diagnoses were identical in all cases. One patient thought to have a left middle cerebral bifurcation aneurysm had only a tortuous vessel and did not need intervention.

In addition to helping achieve accurate diagnoses, the surgical planning data was useful in selecting appropriate intervention. Two patients were treated with stereotactic radiosurgery based on their radiographic diagnoses, volume calculations, and locations of the pathological abnormalities within eloquent cortex. The planning data indicated the lesion volume was within the limits set for radiosurgical methods and that the vessels were within eloquent cortex, eliminating surgical excision as a therapeutic option.

In all surgical cases, the three-dimensional imaging allowed accurate evaluation of the lesions' anatomic location and relationships as well as feeding and draining vessel anatomy. In addition, the images allowed preoperative evaluation of various surgical approaches and the impact each approach might have on surrounding anatomy (i.e., surgical risk). Video registration techniques were successfully used for Patients 15 and 16 for intraoperative localization of subcortically located cavernous malformations. The outcomes for all patients who underwent surgical and radiosurgical treatment were excellent. Some illustrative cases are presented below.

\section{Patient 9}

This 46-year-old man presented with chronic headache. Contrast-enhanced CT and MR images showed a suspected aneurysm in his left middle cerebral artery. The frontal view of the three-dimensional time-of-flight MR angiogram indicated the possibility of a coiling vessel (Fig. 1A). A three-dimensional reconstruction was made from the original $60 \mathrm{MR}$ angiograms. Observation from various directions proved the suspected aneurysm to be a coiling vessel (Fig. 1, B and C). Thus, the patient did not need further evaluation or treatment. The quality of the reconstructions was so precise that an angiogram was not recommended.

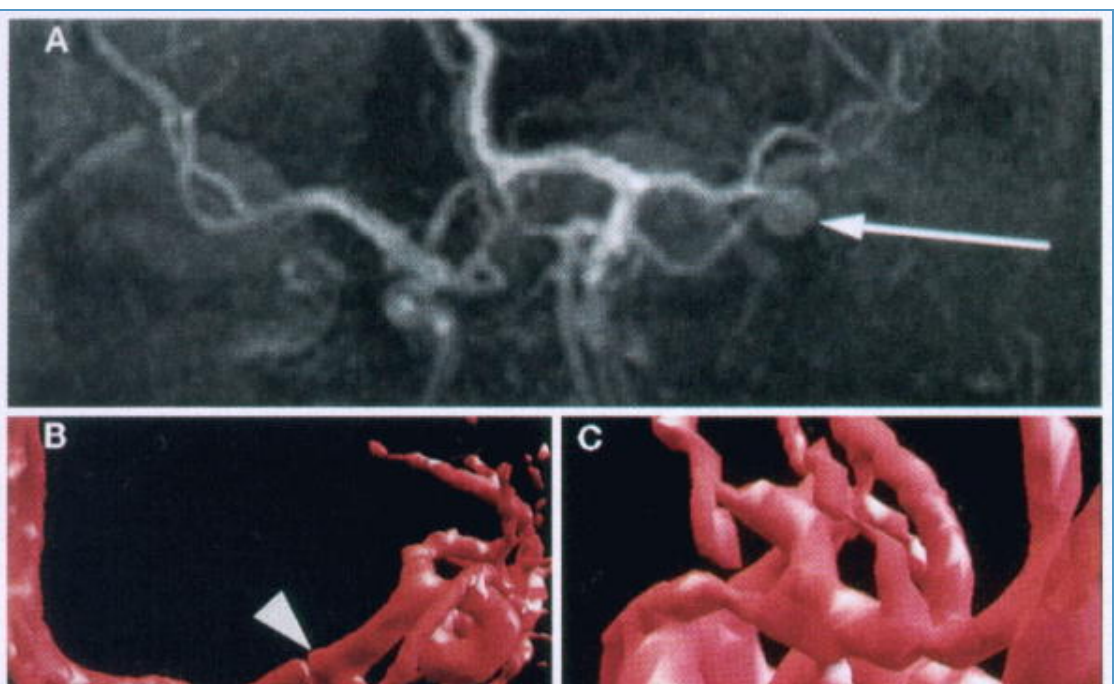




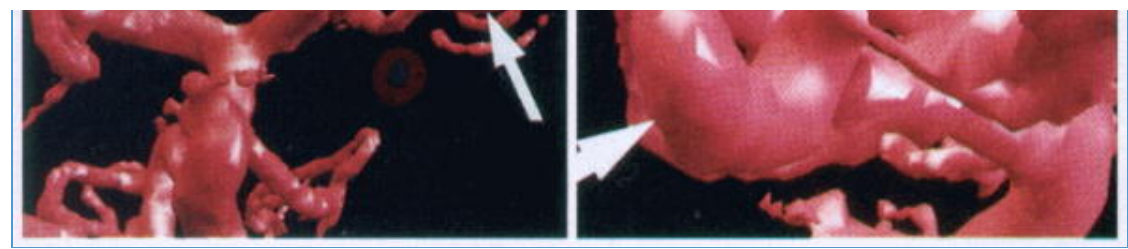

FIGURE 1. $A$, frontal view of the maximum intensity projection display of an MR angiogram showing a suspected left middle cerebral artery aneurysm (arrow). B, oblique frontal view of the three-dimensional model showing coiling of the left middle cerebral artery (arrow) and M1 segment of left middle cerebral artery (arrowhead). C, left lateral view of the three-dimensional model also shows coiling of the left middle cerebral artery (arrow).

Patient 13

This 42-year-old woman presented with incidental AVMs. A three-dimensional model was made from a threedimensional phase contrast MR angiogram acquired with an encoding velocity of $60 \mathrm{~cm}$ per second. Analysis of three-dimensional flow direction $(4,21)$ on the three-dimensional model demonstrated outflow of two vessels from the nidus (Fig. 2D). Therefore, the vessels were thought to be deepseated draining veins, and one of the veins flew into the straight sinus via the great vein of Galen. The AVMs were Spetzler-Martin Grade IV (23) and had an intranidal aneurysm. Multiple surgical approaches were evaluated in the laboratory, and the result of these efforts indicated moderate risk for morbidity. Because of the surgical risk, the patient elected to undergo stereotactic radiosurgery.
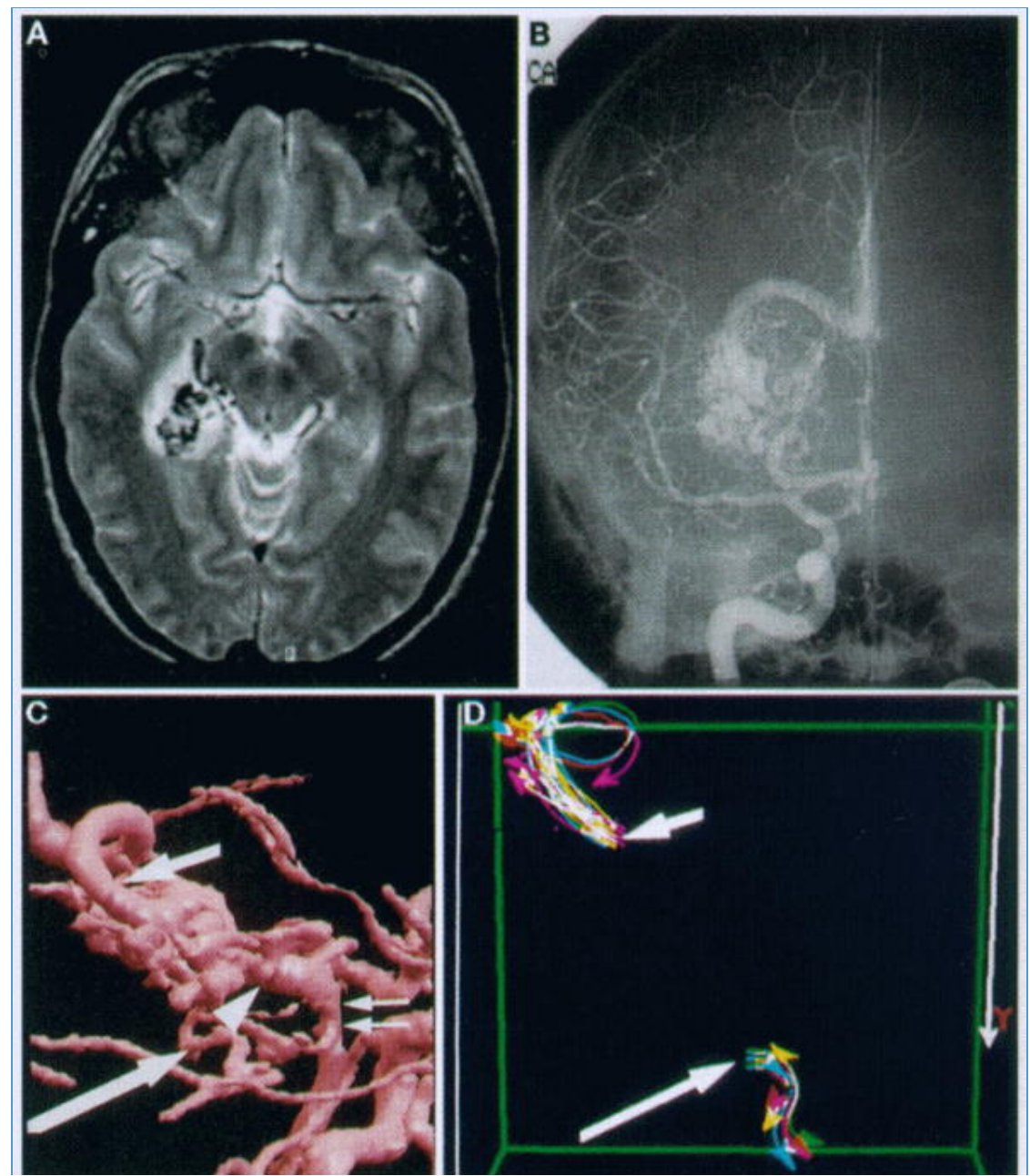
FIGURE 2. A, T2-weighted axial MR image showing right medial temporo-occipital AVMs. $B$, frontal view of the cerebral angiogram showing the nidus fed by the right posterior cerebral artery and draining into the straight

sinus. $C$, right lateral view of the MR angiogram showing the AVMs fed by the basilar artery(double arrows) and right posterior cerebral artery(arrowhead). The long and short arrows indicate the starting points of flow direction analysis. $D$, lines show the flow direction from the nidus. The long and short arrows show the same points as shown in Panel $C$.

Patient 8

This 18-year-old male patient presented with a sudden and severe headache. The MR image showed an intraventricular hemorrhage. A three-dimensional model was made from the three-dimensional phase contrast angiogram with an encoding velocity of $60 \mathrm{~cm}$ per second. The nidus seemed to be close to the inferomedial wall of the left trigone. Two surgical approaches were investigated and compared (3, 15)(Fig. 3, C and D). An occipital transcortical, transventricular approach provided a straight trajectory and a wide working space after evacuating the hematoma in the trigone. The disadvantage of the approach was that it could potentially damage the optic radiations (Fig. 3C). The three-dimensional model showed that another possible approach was the suboccipital supratentorial approach. There was no large bridging vein between the left transverse sinus and the occipital lobe close to the approaching site. This approach seemed as though it would not damage the visual cortex or the optic radiations and was eventually used (Fig. 3D). The nidus was entirely removed without neurological deficit.
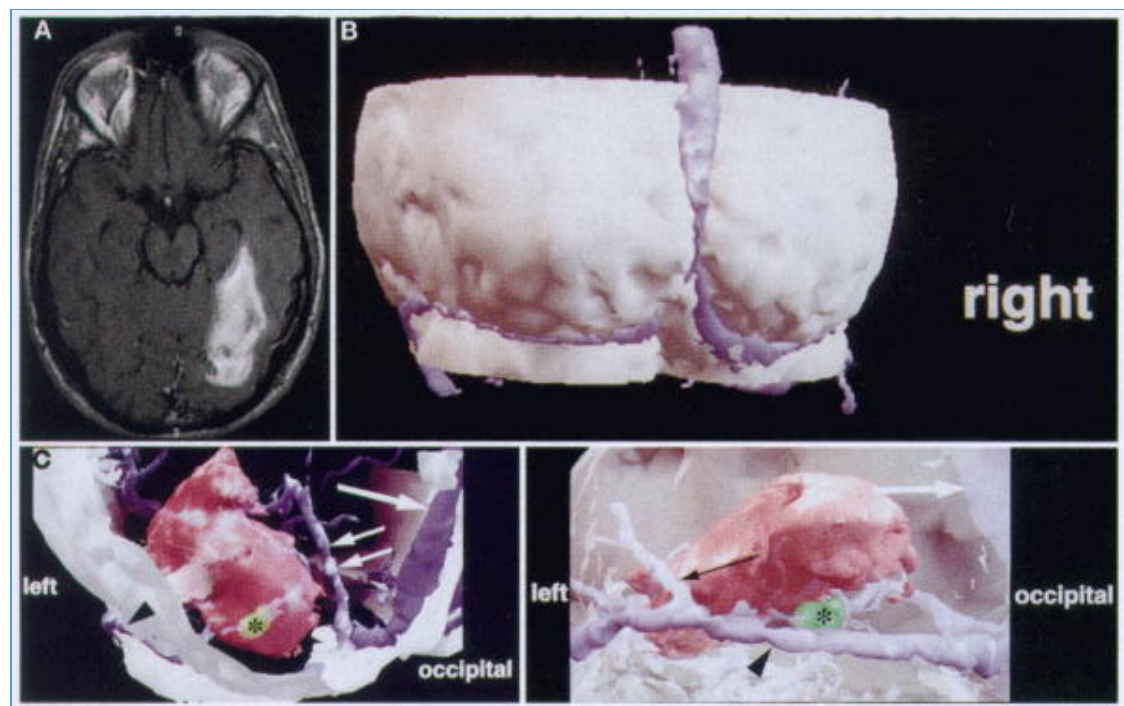

FIGURE 3. A, axial T1-weighted image showing a hematoma in the left trigone. $B$, left posterior view of the threedimensional model. The superior sagittal sinus and left transverse sinus are shown in blue. $C$, computer-assisted 
sımutatıon or tne transcortıcal, transventricutar approacn to tne nıaus. Ine nıaus (green, asterısk), intraventricutar hematoma (pink), superior sagittal sinus (arrow), straight sinus (double arrows), and transverse sinus (arrowhead) DISGISSSISN.$D$, computer-assisted simulation of the suboccipital, supratentorial approach to the nidus. The nidus (green, asterisk), superior sagittal sinus (white arrow), transverse sinus(arrowhead), and the vein of Labbé (black

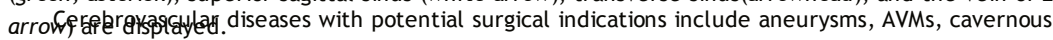
malformations, and occlusive vascutar diseases. The current routine examination for these diseases are cerebral angiography and digital subtraction angiography. In addition, three-dimensional CT angiography $(2,6,16,22,25)$ and MR angiography $(11,12)$ have become available. These new modalities are less invasive, and the image quality is steadily improving. However, there are still some limitations associated with these new techniques. For example, the maximum intensity projection display, which is the most conventional method for displaying a simple three-dimensional image of the MR angiogram, makes it difficult to visualize depth information (1). In addition, this method is not capable of separating each anatomic structure. However, the original CT and MR data can be manipulated to provide the surgeon with greater volume, anatomic, and flow information. There is a need to use the data from these new imaging modalities more efficiently.

Our approach is to use a surface-rendering three-dimensional reconstruction method using MR angiograms or MR images (7-9). There are several advantages to this, as compared to current radiological techniques. First, the examination is less invasive than that with cerebral angiography or digital subtraction angiography. Second, each three-dimensional object can be made translucent, removed, and rotated with a mouse-controlled cursor and lesions can be observed from various directions. The viewer can easily understand the morphology of complicated structures or get a "surgeon's eye view" before the operation. Third, encoding the velocity allows identification of arteries and veins (11). That means that if our interest is a high-flow region, such as an aneurysm or the carotid artery, we can set the encoding velocity to $60 \mathrm{~cm}$ per second. On the other hand, if the region of interest contains a low-flow structure, such as cortical arteries or veins, we can set the encoding velocity at 10 to $20 \mathrm{~cm}$ per second. This allows us to differentiate feeding arteries and draining veins in the axial MR images. The MR data are used during surgical resection of AVMs when differentiating arteries and veins, which, when viewed grossly, appear similar. Therefore, optimized data acquisition and appropriate image processing can provide useful information for cerebrovascular disease treatment.

A three-dimensional phase contrast angiogram has velocity information in the three orthogonal directions, such as left-right, anteroposterior, and superoinferior (11, 12, 21), and the data can be used for surgical planning as well. It is important to distinguish feeding arteries from draining veins in cases of AVMs when planning the surgical approach. With this method, we can determine the flow direction in relation to the AVMs and thereby distinguish arteries and veins. Thus far, we have used this technique only preoperatively for AVMs, but we plan to evaluate the effects of embolization on flow in the future. In addition, this technique allows visualization of surface veins, facilitating our understanding of the superficial cortical anatomy when planning a surgical approach.

The three-dimensional model can be used for surgical planning as well as diagnostic and treatment purposes. Our surgical planning for cerebrovascular surgery consists of three steps. The first step is to select the best treatment modality. Because most cerebrovascular diseases are not malignant, there always is a conservative option. The three-dimensional model provides detailed and precise anatomic information, which is important in determining the surgical indications. The second step is to choose the therapeutic intervention. In addition to surgery, angiographic interventional techniques $(10)$ and radiosurgery $(18,24)$ are currently available for the treatment of vascular malformations. The third step is to select the surgical approach. The spatial relationship of each anatomic structure is clarified using a three-dimensional model. All possible surgical approaches can be explored interactively on the computer display. In addition, visualization of the associated anatomy by a threedimensional image enables residents to understand spatial tissue relationships and to visualize various approaches preoperatively.

Validation for the accuracy of registration was assessed in two ways. Preoperative planning using the threedimensional data facilitated localization of the lesion in 8 of the 11 cranial cases such that no additional localizing technique was needed. In two cases, three-dimensional data with intraoperative video registration was successfully used to locate subcortical cavernous malformations $(14,20)$. Thus, our experience suggests these techniques improved localization subjectively and are useful for devising treatment plans for patients with various vascular conditions.

Our method, however, has limitations and needs improvement. Our segmentation is based on a simple filtering, thresholding, and connectivity method. Although we can generate the three-dimensional model in a very short time with this method, the completed three-dimensional model loses detailed structure. We are considering using more sophisticated postprocessing methods, such as appropriate filtering or segmentation with an expectation-maximizing algorithm (26). We do not fully exploit the three-dimensional phase contrast angiographic information for every patient, because the cumulative data are too many and we do not have an appropriate method to display a comprehensive three-dimensional model. We are currently developing tools to display both the three-dimensional model and the original image data simultaneously. Finally, there is the issue of phase wrap artifacts in the three-dimensional phase contrast angiograms. That is, blood flow rates higher than the selected encoding velocity can cause severe artifacts (21). Therefore, use of phase contrast angiography requires a thorough understanding of the potential artifacts induced by current MR acquisition techniques. Several groups are researching methods to overcome these limitations (5).

In the future, our method can be applied to other areas of cerebrovascular disease treatment. For example, we are attempting to apply our method to the virtual superselective angiogram, the compartmentalizing of the AVMs based on the draining vein (27), postoperative follow-up examinations of occlusive diseases, and in the management of vasospasm. A less invasive and more reliable velocity analysis makes the above goals possible. All of these studies focus on the evaluation of flow information from three-dimensional phase contrast angiograms, which can be postprocessed to render this information. We have also started a new three-dimensional surgical 


\section{ACKNOWLEDGMENTS}

We acknowledge many of our colleagues for help and support in this work. In particular, we thank David Metcalf, Adam Shostack, Mark Anderson, Marianna Jakab, William Wells, Hiroshi Shinmoto, Nobuhiko Hata, Sarajune Dagen, Maureen Ainslie, and Mary Knapman. Ron Kikinis and Ferenc Jolesz were supported in part by National Institutes of Health Grant P01-CA67165.

\section{REFERENCES}

1. Anderson CM, Saloner D, Tsuruda JS, Shapeero LG, Lee RE: Artifacts in maximum-intensity-projection display of MR angiograms. AJR Am J Radiol 154:623-629, 1990. ExternalResolverBasic| [Context Link]

2. Aoki S, Sasaki Y, Machida T, Ohkubo T, Minami M, Sasaki Y: Cerebral aneurysms: Detection and delineation using 3-D-CT angiography. AJNR Am J Neuroradiol 13:1115-1120, 1992. ExternalResolverBasic| [Context Link]

3. Batjer H, Samson D: Surgical approaches to trigonal arteriovenous malformations. J Neurosurg 67:511-517, 1987. ExternalResolverBasic| [Context Link]

4. Bhalerao AH, Summers PE: A multiresolution approach to flow feature extraction from phase contrast MRA. Proceedings of Information Processing in Medical Imaging, Brest, France, 1995, pp 397-398. [Context Link]

5. Bhalerao A, Westin C-F, Kikinis R: Unwrapping phase in 3D MR phase contrast angiograms. Proceedings of First Joint Conference of CVRMed (Computer Vision, Virtual Reality and Robotics in Medicine) II and MRCAS (Medical Robotics and Computer Assisted Surgery) III, Grenoble, France, 1997, pp 193-202. [Context Link]

6. Castillo M, Wilson JD: CT angiography of the common carotid artery bifurcation: Comparison between two techniques and conventional angiography. Neuroradiology 36:602-604, 1994. ExternalResolverBasic| [Context Link]

7. Cline HE, Dumoulin CL, Lorensen WE, Hart HR, Ludke S: $3 D$ reconstruction of the brain from magnetic resonance images using a connectivity algorithm. Magn Reson Imaging 5:345-352, 1989. [Context Link]

8. Cline HE, Lorensen WE, Kikinis R, Jolesz FA: Three-dimensional segmentation of MR images of the head using probability and connectivity. J Comput Assist Tomogr 14:1037-1045, 1990. Ovid Full Text| ExternalResolverBasic| [Context Link]

9. Cline HE, Lorensen WE, Souza SP, Jolesz FA, Kikinis R, Gerig G, Kennedy TE: 3D surface rendered MR images of the brain and its vasculature: Technical note. J Comput Assist Tomogr 15:344-351, 1991. Ovid Full Text| ExternalResolverBasic | [Context Link]

10. Debrun G, Viñuela F, Fox A, Drake CG: Embolization of cerebral arteriovenous malformations with bucrylate: Experience in 46 cases. J Neurosurg 56:615-627, 1982. ExternalResolverBasic| [Context Link]

11. Dumoulin C, Souza S, Walker M, Wagle W: Three-dimensional phase contrast angiography. Magn Reson Med 9:139-149, 1989. ExternalResolverBasic| [Context Link]

12. Edelman RR: MR angiography: Present and future. AJR Am J Radiol 161:1-11, 1993. ExternalResolverBasic| [Context Link]

13. Gerig G, Kubler O, Kikinis R, Jolesz FA: Nonlinear anisotropic filtering of MRI data. IEEE Trans Med Imaging 11:221-232, 1992. [Context Link]

14. Gleason PL, Kikinis R, Altobelli D, Wells W, Alexander E III, Black PMCL, Jolesz F: Video registration virtual reality for nonlinkage stereotactic surgery. Stereotact Funct Neurosurg 63:139-143, 1994. ExternalResolverBasic| [Context Link]

15. Heros RC: Arteriovenous malformations of the medial temporal lobe: Surgical approach and neuroradiological characterization. J Neurosurg 56:44-52, 1982. ExternalResolverBasic| [Context Link] 
16. Hsiang JNK, Liang EY, Lam JMK, Zhu X-L, Poon WS: The role of computed tomographic angiography in the diagnosis of intracranial aneurysms and emergent aneurysm clipping. Neurosurgery 38:481-487, 1996. Ovid Full Text | ExternalResolverBasic| [Context Link]

17. Kikinis R, Gleason PL, Moriarty TM, Moore MR, Alexander E III, Stieg PE, Matsumae M, Lorensen WE, Cline HE, Black PMCL, Jolesz FA: Computer-assisted interactive three-dimensional planning for neurosurgical procedures. Neurosurgery 38:640-651, 1996. Ovid Full Text| ExternalResolverBasic|[Context Link]

18. Kjellberg RN, Hanamura T, Davis KR, Lyons SL, Adams RD: Bragg-peak proton-beam therapy for arteriovenous malformations of the brain. N Engl J Med 309:269-274, 1983. ExternalResolverBasic|[Context Link]

19. Koyama T, Okudera H, Kobayashi S: Computer-assisted geometric design of cerebral aneurysms for surgical simulation. Neurosurgery 36:541-547, 1995. Ovid Full Text| ExternalResolverBasic|[Context Link]

20. Nakajima S, Atsumi H, Kikinis R, Moriarty TM, Metcalf DC, Jolesz FA, Black PMcL: Use of cortical vessel registration for image-guided neurosurgery. Neurosurgery 40:1201-1210, 1997. Ovid Full Text| ExternalResolverBasic| [Context Link]

21. Permicone JR, Siebert JE, Laird TA, Rosenbaum TL, Potchen EJ: Determination of blood flow direction using velocity-phase image display with 3-D phase-contrast MR angiography. AJNR Am J Neuroradiol 13:1435-1438, 1992. [Context Link]

22. Schwartz RB: Neuroradiological applications of spiral CT. Semin Ultrasound CT MR 15:139-147, 1994. ExternalResolverBasic| [Context Link]

23. Spetzler RF, Martin NA: A proposed grading system for arteriovenous malformations. J Neurosurg 65:476-483, 1986. ExternalResolverBasic| [Context Link]

24. Steiner L: Treatment of arteriovenous malformations by radiosurgery, in Wilson CB, Stein BM (eds): Intracranial Arteriovenous Malformations. Baltimore, Williams \& Wilkins, 1984, pp 295-314. [Context Link]

25. Tampieri D, Leblanc R, Pleszek J, Pokrupa R, Melançon D: Three-dimensional computed tomographic angiography of cerebral aneurysms. Neurosurgery 36:749-755, 1995. Ovid Full Text| ExternalResolverBasic| [Context Link]

26. Wells W, Kikinis R, Grimson W, Jolesz F: Statistical intensity correction and segmentation of magnetic resonance image data. Proceedings of The Third Conference on Visualization in Biomedical Computing, Rochester, Minnesota, 1994, pp 13-25. [Context Link]

27. Yamada S, Brauer FS, Knierim DS: Direct approach to arteriovenous malformations in functional areas of the cerebral hemisphere. J Neurosurg 72:418-425, 1990. ExternalResolverBasic| [Context Link]

\section{COMMENTS}

In this article, computer-generated three-dimensional color reconstructions of thin-slice gradient magnetic resonance (MR) images are beautifully illustrated. Undoubtedly, such techniques will come into widespread use in time. However, because it takes several hours to generate such pictures and because it likely requires a very high level of sophistication in computers and radiology, it seems unlikely that the current gold standard of digital subtraction angiography will be replaced by this new technique. Although I agree that the figures are helpful, I do not think they provide any information that cannot be gleaned from well-performed angiography.

Because of the recent advances in functional localization using MR techniques, it is easy to speculate that in the near future, we will use three-dimensional reconstructions that indicate the precise vasculature and the localization of pertinent neurological functions. This is a marvelous technology, and I can well understand the authors' enthusiasm for it. However, I am not persuaded that this technique is likely to result in less morbidity than that which results using other currently available standard diagnostic techniques.

Bryce K.A. Weir

Chicago, Illinois 
This is an important contribution. The authors developed, applied, and evaluated the use of a sophisticated three-dimensional MR imaging(MRI) system for surgical planning. Nakajima et al. think that their computergenerated three-dimensional reconstructions of MRI data allowed them to better select the most appropriate surgical or nonsurgical therapy, assess the degree of operative risk for the patient during surgery, choose the least disruptive surgical approach for these lesions, and improve resident teaching. The authors also point out the present limitations of the system and discuss plans for improvement. Our experience with less sophisticated three-dimensional computed tomographic angiographic reconstructions generally parallels their experience with the three-dimensional MRI reconstructions that are presented here $(1,2)$.

I think that the most interesting aspect, and perhaps the greatest value of this planning system, lies in its ability to evaluate the direction and velocity of blood flow. This information is not available with the use of threedimensional computed tomographic angiography and is difficult to obtain and quantitate from digital subtraction angiography. Because of this feature, the system has considerable promise for evaluating patients with arteriovenous malformations (AVMs), vasospasm, and occlusive cerebrovascular disease.

The authors state that AVMs in eloquent cortex should be eliminated from surgical consideration. Cerebrovascular neurosurgeons, including the senior author of this article, have removed AVMs from eloquent cortex without incurring persistent neurological deficits. Although location of AVMs in eloquent cortex should raise the level of concern for microsurgical excision of the lesion, it does not rule out this treatment option. The two patients treated with radiosurgery achieved excellent outcomes, although there are no data presented to indicate that their AVMs were obliterated after therapy. I suppose that they underwent post-treatment angiography that demonstrated no residual AVMs. If not, the designation of such an outcome as excellent is highly questionable.

The more important question raised by this article is how to determine the value of this or any other innovative technology. The results in these patients were excellent. However, I have a strong suspicion that Stieg would have achieved the same excellent results without the use of this sophisticated planning system. How do we determine whether the resources that went into generating and applying the three-dimensional MRI reconstructions resulted in better patient care? There is no easy answer. It is unquestionably important for neurosurgery to continue to develop and apply the best technological advances for the care of our patients. However, we may reach a point of diminishing returns and we need to think about how to assess the benefits that may, or may not, accrue with the next technological advance. Technology is seductive, and there is a predisposition to think that the more technology we bring to bear on a clinical problem, the better the results. This hypothesis, like any other, needs to be tested, particularly in an era of increasing competition for research and clinical resources. It is inappropriate to take the Luddite approach of staunchly resisting all new technology. It is equally inappropriate to accept as a tenet of faith that making our virtual patients more realistic will cure the real ones.

Robert E. Harbaugh

Lebanon, New Hampshire

1. Harbaugh RE, Schlusselberg DS, Jeffery R, Hayden S, Cromwell LD, Pluta D: Three-dimensional computerized tomography angiography in the diagnosis of cerebrovascular disease. J Neurosurg 76:408-414, 1992. ExternalResolverBasic| [Context Link]

2. Harbaugh RE, Schlusselberg DS, Jeffery R, Hayden S, Cromwell LD, Pluta D, English RA: Three-dimensional computed tomography angiography in the preoperative evaluation of cerebrovascular lesions. Neurosurgery 36:320327, 1995. Ovid Full Text| ExternalResolverBasic| [Context Link]

This report assesses the experience of a distinguished group of authors with computer-assisted surgical planning using segmental, rendered images of cerebrovascular anatomy. The clinically significant, anatomically complex structural relationships present in cerebrovascular disorders make desirable any technique that enhances the neurosurgeon's interactive analysis of three-dimensional structures. A requisite skill acquired during neurosurgical training is the conceptual integration of multiple two-dimensional projection angiographic images. The inherently three-dimensional nature of magnetic resonance angiography, computed tomographic angiography, and similar digital imaging techniques has promised a source of superior display of this information. The authors have taken a critical step in the process of evolving surgically useful protocols for manipulating digital tomographic images. Notably, they have observed clinical benefit from even these preliminary efforts.

The authors also present a discussion that acknowledges a number of concerns that are present in the neurosurgical community about the use of these digital flow-derived images for surgical treatment planning. Significant spatial distortions are present in all MR angiographic images, and some of these distortions resist current methods of rectification. Additional errors are introduced during the process of registration of images to other images and to physical space, requiring neurosurgeons who proceed along this path to critically assess the validity of their results. The process of segmentation and three-dimensional rendering of digital information inevitably discards information; this loss must be weighed against the benefits of improved visualization of anatomic relationships using these processed images. The aesthetic impact and visually compelling nature of pseudo-three-dimensional rendered images can even prove to be dangerous when the display proves more apparent than real. Confirming the validity of increasingly complex displays of visual information will be crucial to

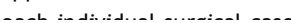


Improved visualization technologies promise to be a major area of research and development in the near future. This will have real impact on surgical planning, simulation and training, intraoperative display, and patient education. The scientific communication of these advances will likely be best displayed by vehicles of electronic publishing rather than traditional print journals.

Robert J. Maciunas

Nashville, Tennessee

Key words: Cerebrovascular disease; Image-guided neurosurgery; Magnetic resonance imaging; Phase contrast magnetic resonance angiography; Three-dimensional reconstruction

\section{IMAGE GALLERY}

Select All

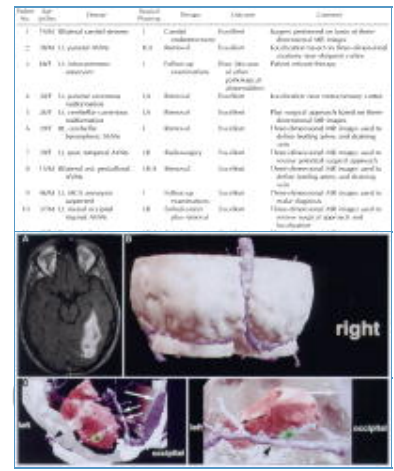

Figure 3

Back to Top

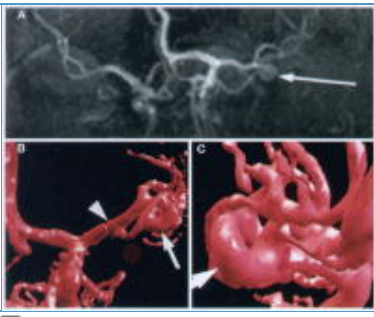

$\square$ Figure 1
Export Selected to PowerPoint

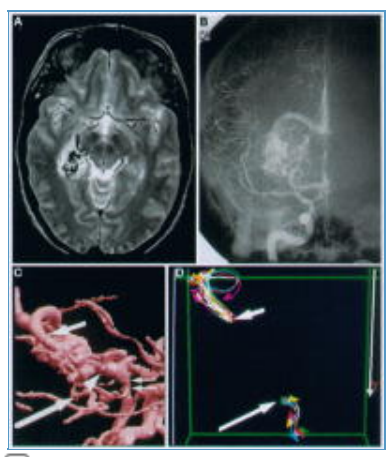

Figure 2
Copyright (c) 2000-2011 Ovid Technologies, Inc.

Terms of Use | Support \& Training | About Us | Contact Us

Version: OvidSP_U103.04.01.113, SourcelD 54495 